\title{
Assessing the impact of total extracorporeal circulation on hemodynamics in an ovine fetal model
}

\author{
FEI XIAO, JIAN ZHUANG, CHENG-BIN ZHOU, JI-MEI CHEN, \\ JIAN-ZHENG CEN, GANG XU and SHU-SHENG WEN \\ Department of Pediatric Cardiovascular Surgery, Guangdong Provincial Cardiovascular Institute, \\ Guangdong General Hospital, Guangzhou, Guangdong 510100, P.R. China
}

Received December 22, 2015; Accepted February 7, 2017

DOI: $10.3892 /$ etm.2017.4831

\begin{abstract}
The present study aimed to evaluate the impact of total extracorporeal circulation on hemodynamics and placental function in an ovine fetal model. Mid-term ovine fetuses ( $\mathrm{n}=6$ ) underwent extracorporeal circulation (30 min), cardioplegic arrest (20 min) and monitoring (120 min). The ascending aorta and umbilical cords of the fetuses were occluded during the bypass and an extracorporeal membrane oxygenator was used as the oxygen source. Biventricular intracardiac pressures, echocardiographic data, blood gas levels and placental function variables were recorded, and statistical analysis was performed using the repeated-measure analysis of variance test. The data indicated that fetal heart rate and blood pressure at 30, 60,90 and $120 \mathrm{~min}$ following the bypass were stable relative to pre-arrest baseline (pre-bypass) values $(\mathrm{P}>0.05)$. However, end diastolic pressures in the ovine right ventricles post-bypass were significantly increased at 30,60, 90 and 120 min relative to pre-bypass pressures $(\mathrm{P}<0.05)$. The pulsatility index also increased at $30 \mathrm{~min}$ post-bypass relative to the pre-bypass score $(0.91 \pm 0.06$ vs. $0.61 \pm 0.14 ; \mathrm{P}=0.007)$. The mean resistivity index at all time points post-bypass was consistent with the pre-bypass score $(\mathrm{P}>0.05)$, while the mean Tei index values for the left and right ventricles post-bypass were significantly higher at all time points relative to pre-bypass values $(\mathrm{P}<0.05)$. The pre-bypass fetal blood $\mathrm{pH}$, $\mathrm{SaO}_{2}$, base excess and lactate values were maintained during arrest $(\mathrm{P}>0.05)$. Fetal hemodynamics and placental function additionally remained stable for up to $2 \mathrm{~h}$ upon reperfusion following total extracorporeal circulation and cardioplegic arrest. Collectively these data suggest that the reproducible
\end{abstract}

Correspondence to: Dr Jian Zhuang, Department of Pediatric Cardiovascular Surgery, Guangdong Provincial Cardiovascular Institute, Guangdong General Hospital, 96 Dongchuan Road, Guangzhou, Guangdong 510100, P.R. China

E-mail: zj96_jianzhuang@sina.com

Key words: cardioplegia, cardioplumonary bypass, extracorporeal circulation, hemodynamics, extra-corporeal membrane oxygenator, ovine fetus ovine fetal model may be useful in the evaluation of fetal cardiac surgery.

\section{Introduction}

Congenital heart disease (CHD) accounts for $1 \%$ of congenital malformations in humans (1). Despite improvements in the diagnosis of CHD, morbidity and mortality rates remain high for severe heart defects during the fetal and neonatal periods, and generally cannot be corrected using anatomical or physiological methods, requiring palliative surgery instead $(2,3)$. The morbidity of congenital heart disease is $\sim 1 \%$, and complex congenital heart disease accounts for $20 \%$ (1). Complex congenital heart malformations are the cause of significant mortality and morbidity in human fetuses, either in utero or shortly after birth (4), thereby affecting the lifespan and prognosis of children with CHD. The average life expectancy of patients with congenital heart malformations is significantly lower than that of health people (5). Furthermore, severe primary congenital heart defects may subsequently cause progressive secondary heart damage, which may exceed that of the primary defect. For example, damage such as vascular dysplasia and macrovascular dysplasia may occur due to abnormal hemodynamics during the fetal period, resulting in severe pathological changes, including single ventricle defects and severe heart dysfunction, occurring, which may lead to mortality (5-9). In particular, previous studies have identified severe coarctation of the aorta or aortic atresia, causing dysplasia of the aortic arch or left ventricle (7); pulmonary atresia or tricuspid atresia with an intact ventricular septum, resulting in right ventricular dysplasia; Ebstein's malformation of the tricuspid valve, resulting in functional pulmonary atresia (6); and severe damage to the vascular bed of the fetal lung as forms of secondary damage $(5,8,9)$. These may be avoided by in utero correction of primary defects, which may potentially preserve fetal development (10).

Fetal sheep physiology is similar to that of humans, enabling the use of sheep as a common model for translational research in the field of cardiovascular surgery (11). Cardiopulmonary bypass $(\mathrm{CPB})$ was investigated in early studies of fetal heart surgery conducted in the 1980s $(10,12)$, with the use of ovine models to evaluate the fetal pathological response to CPB emerging in the 1990s $(13,14)$. CPB techniques in fetal sheep include protective measures for fetal cardiac arrest and cardiac 
function $(15,16)$, and the establishment of fetal cardiac arrest and resuscitation models. In a previous study by our group, an in vivo goat model of fetal CPB with cardioplegic arrest was established, which provided reproducible data and appeared to be suitable for studying fetal CPB, myocardial protection and hemodynamics (17). Establishing a safe and effective animal model of CPB and fetal cardiac arrest in order to evaluate functional protection of the fetal heart and placenta, is necessary for fetal open-heart surgery (11). A successful model requires an effective circulatory support system, a technique for performing safe fetal cardiac arrest and protective measures available for the fetal myocardium and placenta. In addition, post-operative fetal cardiac function and placental function must be maintained to enable development of the fetal sheep following in utero surgery, as this is likely to enable successful future treatment of CPB and open heart surgery in humans $(14,15)$.

In establishing an animal model of CPB, it has not been determined whether membrane oxygenation can be used as the sole oxygenator, and whether the placenta can be isolated from the extracorporeal circulation (ECC) system. The present study aimed to establish a complete animal model, by preserving the fetal heart and placental function in an extracorporeal ovine fetus model with placental blocking, fetal cardiac arrest, fetal heart resuscitation, placental opening, withdrawal of CPB, and clamping of the ascending aorta and umbilical cord. This was expected to enable study into the safety and effectiveness of the ovine model, while evaluating the hemodynamics of fetal sheep-placental circulation following withdrawal of CPB.

\section{Materials and methods}

Animal model. A total of 6 singleton-bearing pregnant ewes (age, $21-24$ months; $26.5+7.1 \mathrm{~kg}$ ) at mid-term gestation (110-130 days) were studied (ovine full-term, 150 days). Ewes were fed with a standard diet, with access to water ad libitum at $14-22^{\circ} \mathrm{C}$ with $50-70 \%$ humidity, and the light/dark cycle was $12 \mathrm{~h}$. The ewes were purchased from Inner Mongolia Academy of Animal Science (Huhhot, China). Ethical approval was granted by the Research Ethics Committee of Guangdong General Hospital (Guangzhou, China). The ewes fasted for $24 \mathrm{~h}$ prior to induction of anesthesia by intramuscular injection of 10-20 mg/kg ketamine (Fujian Gutian Yuanhang Medical Company, Ltd., Ningde, China). Anesthesia was maintained with $5 \mu \mathrm{g} / \mathrm{kg} / \mathrm{h}$ intravenous fentanyl (Yichange Renfu Pharmaceutical Co., Ltd., Yichang, China) and $0.4 \mathrm{mg} / \mathrm{kg} / \mathrm{min}$ intravenous propofol (Guangdong Jiabo Pharmaceutical Co., Ltd., Shanghai, China). The ewes were then intubated and mechanically ventilated with $40 \%$ oxygen. An intravenous injection of vecuronium bromide $(0.1 \mathrm{mg} / \mathrm{kg}$; Zhejian Xianju Pharmaceutical Co., Ltd., Taizhou, China) was used to induce muscle relaxation. Catheters were placed in the maternal left femoral artery and vein to deliver 5\% glucose saline and for blood collection to allow measurement of blood gas levels. Following midline laparotomy and minor hysterectomy to obtain fetuses, catheters were placed in the fetal left elbow artery for continuous collection of blood samples and monitoring of arterial blood pressure. The fetuses underwent median sternotomies and cannulation and were placed on fetal cardiac bypass for $30 \mathrm{~min}$. During the bypass, the ascending aorta and umbilical cords were clamped to induce fetal cardioplegic arrest lasting for $20 \mathrm{~min}$. Hemodynamic values were recorded continuously for 120 min following bypass termination.

Fetal cardiac bypass. Following fetal median sternotomy, heparin (10 mg; Shanghai No. 1 Biochemical and Pharmaceutical Co., Ltd., Shanghai, China) was administered intravenously 5 min prior to cannulation with an $8 \mathrm{~F}$ arterial cannula (Medtronic Inc., Minneapolis, MN, USA) in the pulmonary artery trunk and a $16 \mathrm{~F}$ straight venous cannula (Medtronic, Inc.) in the right atrium. Hemodynamic values were recorded continuously during the experiment. Fetal cardiac bypass was administered with a centrifugal pump system (BP50; Medtronic, Inc.), a baby extra-corporeal membrane oxygenator (LivaNova, PLC, London, UK) and a heat exchanger.

At 3 min following initiation of the bypass, the ascending aorta and umbilical cord were clamped (see below), rendering the ECMO the sole source of oxygen for the fetus. The blood prime for the bypass circuit was collected from 6 non-maternal adult ewes (18-22 months, $24.2 \pm 4.6 \mathrm{~kg})$. Ewes were fed with a standard diet, with access to water ad libitum at $14-22^{\circ} \mathrm{C}$ with $50-70 \%$ humidity, and the light/dark cycle was $12 \mathrm{~h}$. The ewes were purchased from Inner Mongolia Academy of Animal Science. Ethical approval was granted by the Research Ethics Committee of Guangdong General Hospital. Normothermic fetal cardiac bypass was conducted for $30 \mathrm{~min}$ with a mean pump flow rate of $350 \mathrm{ml} / \mathrm{kg} / \mathrm{min}$, according to a previously used method (17). Upon termination of bypass, fetal hemodynamic recordings were monitored continuously for $120 \mathrm{~min}$, as described previously (18-20). Following completion of the studies, the ewes and fetuses were euthanized via an intravenous injection of $50 \mathrm{mg} / \mathrm{kg}$ sodium pentobarbital (Shanghai Xinya Pharmaceutical Gaoyou Co., Ltd., Shanghai, China) and then $10 \mathrm{ml}$ of $10 \%$ potassium chloride (Yangzhou Zhongbao Pharmaceutical Co., Ltd., Yangzhou, China). Death was confirmed when no ECG or blood pressure signals were detected) for autopsies, measurement of fetal weight and confirmation of catheter positions.

Clamping the ascending aorta and umbilical cord. The umbilical cord was clamped immediately upon initiation of ECC, rendering the ECMO the sole source of oxygen for the fetus. Upon reaching a stable target bypass flow rate (300-350 $\mathrm{ml} / \mathrm{kg} / \mathrm{min}$ ) within 2-3 $\mathrm{min}(17)$, the mid-ascending aorta was cross-clamped and a bolus of cold crystalloid induction cardioplegic solution $\left(25 \mathrm{ml} / \mathrm{kg} ; 4^{\circ} \mathrm{C}\right)$; modified calcium-free St. Thomas solution, made in house and comprising $480 \mathrm{ml}$ Ringer's solution (Shijiazhuang Siyao Pharmaceutical Co., Ltd., Shijiazhuang, China), $15 \mathrm{ml} \mathrm{5 \%} \mathrm{sodium} \mathrm{bicar-}$ bonate (Dongya Pharmaceutical Co., Ltd., Jiangxi, China), $0.625 \mathrm{ml} \mathrm{2 \%}$ lidocaine (Shanghai Zhaohui Pharmaceutical Co., Ltd., Shanghai, China), $5 \mathrm{ml} \mathrm{10 \%} \mathrm{potassium} \mathrm{chloride}$ (Yangzhou Zhongbao Pharmaceutical Co., Ltd.), $2.4 \mathrm{ml} 25 \%$ magnesium sulphuricum (Hebei Tiancheng Pharmaceutical Co., Ltd., Hebei, China) and $4 \mathrm{mg}$ dexamethasone (Tianyao Pharmaceutical Co., Ltd., Tianjin, China) was administered as described previously (21). Topical cooling using ice slush was performed for $10 \mathrm{~min}$ and then a second maintenance dose of cardioplegic solution was administered. The perfusion 
A

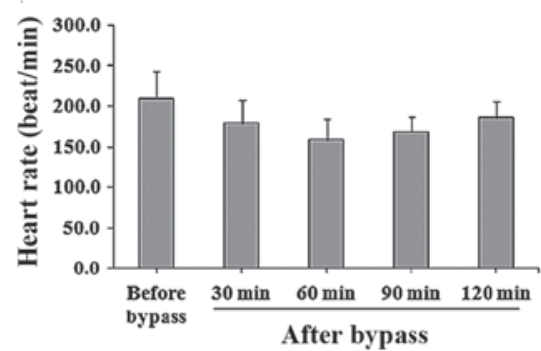

B

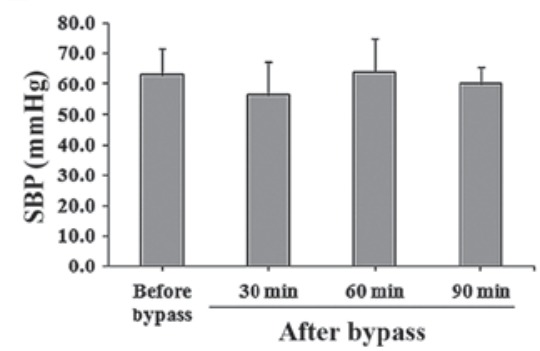

C

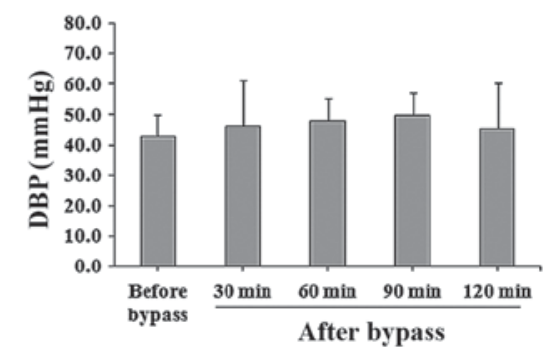

Figure 1. Fetal hemodynamic parameters pre- and post-bypass cessation. The hemodynamic parameters of (A) fetal heart rate, (B) SBP, (C) DBP. Data are presented as the mean \pm standard deviation $(n=6)$. SBP, systolic blood pressure; DBP, diastolic blood pressure.

pressure was maintained at $35-40 \mathrm{mmHg}$, in accordance with previous methods $(17,21)$. While fetal myocardial temperature was lowered to $6-8^{\circ} \mathrm{C}$, systemic fetal temperature was maintained at $38 \pm 1.5^{\circ} \mathrm{C}$. Following $20 \mathrm{~min}$ of myocardial ischemia, the aortic cross-clamp was removed in order to reperfuse the fetal heart. Invariably the fetal heart initiated contractions in a normal sinus rhythm. ECC was continued for 7-8 min until total cardiac bypass time reached $30 \mathrm{~min}$, then the umbilical clamp was removed to allow placental reperfusion. Systemic heparinization was not routinely reversed. Following bypass cessation, fetuses were decannulated and hemodynamic parameters were monitored for $120 \mathrm{~min}$.

Measurements of fetal cardiac function. The following parameters were recorded continuously: Heart rate, blood pressure, peak systolic and end diastolic pressures of the left ventricle (LV) and right ventricle (RV), and the Tei index (an echocardiographic indication of cardiac dysfunction) of the LV and RV. These parameters were recorded at the following time points: Immediately prior to ECC (T1), then at 30 (T3), 60 (T4), 90 (T5) and 120 (T6) min post-bypass. Myocardial functional parameters were not measured during the cardiac bypass (T2) due to dependency on extracorporeal support. Pressure catheters were inserted through the myocardium into the LV and RV for real-time measurements. The sonographic system GE LOGIQ Book XP, equipped with a linear transducer probe for B-mode, color-coded and pulsed-Doppler measurements (4-10 MHz; GE Healthcare, Beijing, China), was used for ultrasonic examinations. The invigilator (GE B650; GE Healthcare Life Sciences, Chalfont, UK) was used to record other parameters. Calculation of the Tei index was calculated according to previous methods $(22,23)$, based on the duration of two time intervals using the formula (A-B)/B, where $A$ was the interval between cessation and onset of mitral inflow (tricuspid inflow) and Bwas LV or RV ejection time.

Measurement of placental resistance. Pulsatility and resistivity indices (PI and RI, respectively) of the umbilical arteries were used to evaluate placental resistance pre- and post-fetal cardiac arrest. The umbilical cord was exposed following completion of fetal cannulation and values were measured with the aforementioned sonographic equipment at the same time points as for the cardiac monitoring ( $\mathrm{T} 1$, T3, T4, T5, T6). The umbilical artery was visualized using color-coded Doppler imaging, according to the following protocol: A pulsed-Doppler flow velocity waveforms sample volume was placed in the center of the color-coded blood flow, then the waveforms of $\geq 3$ consecutive cardiac cycles were recorded, along with the measurements for each waveform. The systolic peak velocity (SPV), end-diastolic velocity (EDV), time-averaged maximum velocity (TAMAX), PI and RI were calculated automatically (PI=SPV-EDV/TAMAX, $\mathrm{RI}=\mathrm{SPV}-\mathrm{EDV} / \mathrm{SPV}$ ).

Blood sampling regimen. Maternal and fetal arterial blood samples were collected for blood gas and metabolite analysis at the following time points: Immediately after arterial access was established; prior to the initiation of ECC (T1); 20 min into cardiac arrest (T2); and 30 (T3), 60 (T4), 90 (T5) and 120 (T6) min following cessation of the bypass. Blood gas and fetal lactate levels were measured with a clinical analyzer (GEM Premier 3000; Werfen Group, Barcelona, Spain).

Statistical analysis. Data are expressed as the mean \pm standard deviation. Data for the set time-points, including during arrest and 30, 60, 90 and 120 min post-bypass were compared with pre-bypass data and analyzed using a linear mixed model test plus a Bonferroni adjustment approach for pair-wise comparisons. Statistical assessments were two-tailed and were performed using SPSS 13.0 software (SPSS Inc, Chicago, IL, USA). $\mathrm{P}<0.05$ was considered to indicate a statistically significant difference.

\section{Results}

Post-bypass fetal heart rate and, blood pressure are stable, whereas ventricular pressures vary. Myocardial parameters were measured at different time points, as depicted in Fig. 1. Fetal heart rate and blood pressure were stable at 30, 60, 90 and $120 \mathrm{~min}$ post-bypass relative to the pre-arrest baseline (pre-bypass) values (P>0.05; Fig. 1A-C). Peak systolic pressure in the LV and RV exhibited no significant changes 30-90 min post-bypass relative to pre-bypass values $(\mathrm{P}>0.05$; Fig. 2A and B). However, peak systolic pressure in the LV significantly decreased at $120 \mathrm{~min}$ post-bypass relative to the pre-bypass value (49.2 \pm 4.1 vs. $61.7 \pm 6.8, \mathrm{P}=0.018$; Fig. $2 \mathrm{~A}$ ). End-diastolic pressure (EDP) in the LV at 30 and $60 \mathrm{~min}$ post-bypass significantly increased relative to the pre-bypass value $(\mathrm{P}<0.01$ and $\mathrm{P}<0.05$, respectively; Fig. $2 \mathrm{C})$. EDP in the RV post-bypass at all time points significantly increased 
A

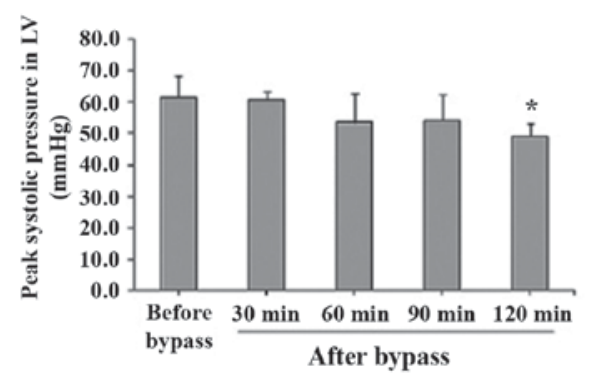

C

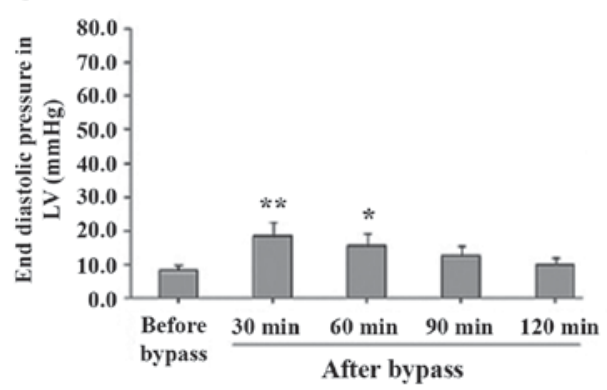

B

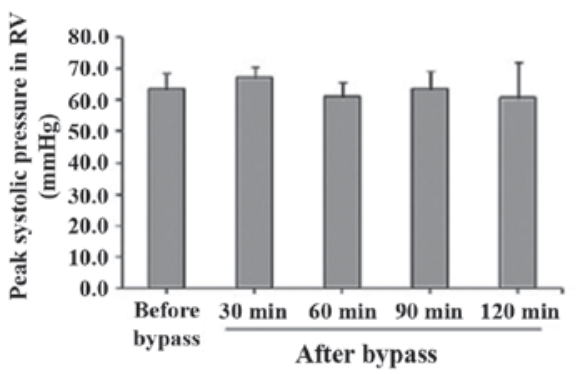

D

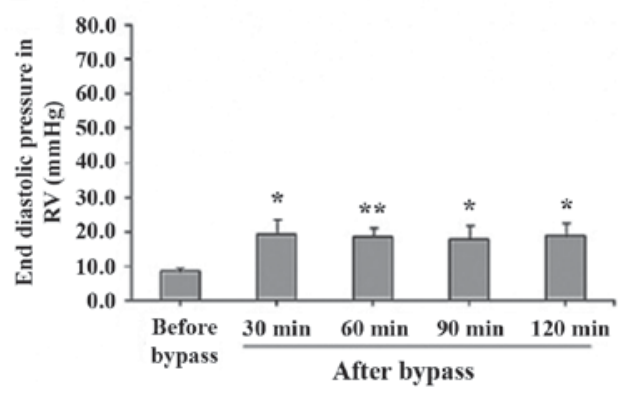

Figure 2. Fetal hemodynamic parameters pre- and post-bypass cessation. The hemodynamic parameters of (A) peak systolic pressure in LV, (B) peak systolic pressure in RV, (C) end diastolic pressure in the LV, (D) end diastolic pressure in the RV. Data are presented as the mean \pm standard deviation $(\mathrm{n}=6)$. ${ }^{*} \mathrm{P}<0.05$ and ${ }^{* *} \mathrm{P}<0.01$ vs. pre-bypass values. LV, left ventricle; $\mathrm{RV}$, right ventricle.

A

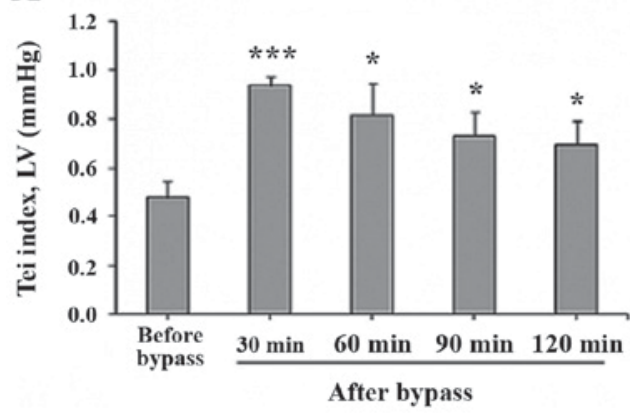

B

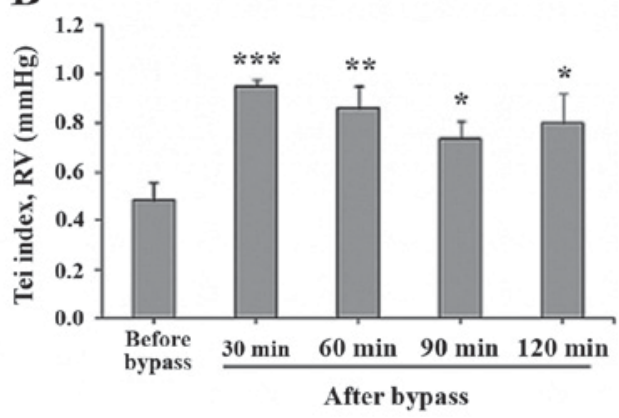

Figure 3. Fetal hemodynamic parameters pre- and post-bypass cessation. The hemodynamic parameters of (A) Tei index of the LV and (B) Tei index of the RV were measured immediately prior to bypass and at set-time intervals $(30,60,90$ and 120 min) post-bypass. Data are presented as the mean \pm standard deviation ( $\mathrm{n}=6) .{ }^{*} \mathrm{P}<0.05,{ }^{* *} \mathrm{P}<0.01$ and ${ }^{* * *} \mathrm{P}<0.001$ vs. pre-bypass values. $\mathrm{LV}$, left ventricle; $\mathrm{RV}$, right ventricle.

relative to the pre-bypass value $(\mathrm{P}<0.05)$, particularly at 60 min post-bypass $(\mathrm{P}<0.01$; Fig. 2D).

Tei index values are significantly increased post-bypass. Mean Tei index was taken as an indication of global cardiac dysfunction in ventricles. The values in the LV and RV over all different time points post-bypass were significantly higher than those pre-bypass $(\mathrm{P}<0.05)$. In particular, this was observed for the LV and RV at $30 \mathrm{~min}(\mathrm{P}<0.001)$ and for the RV at $60 \mathrm{~min}$ ( $\mathrm{P}<0.01$; Fig. 3).

Pulsatility index values are mostly maintained while resistivity index values significantly increase post-bypass. The pulsatility and resistivity index values of the fetal umbilical arteries are depicted in Fig. 2. The pulsatility index significantly increased at $30 \mathrm{~min}$ post-bypass relative to the pre-bypass value $(0.91 \pm 0.06$ vs. $0.61 \pm 0.14, \mathrm{P}=0.007)$, however, no significant changes were observed at 60,90 and $120 \mathrm{~min}$ post-bypass relative to the pre-bypass value ( $\mathrm{P}>0.05$; Fig. $4 \mathrm{~A})$. Mean resistivity index values at all time points post-bypass were consistent with the pre-bypass value ( $\mathrm{P}>0.05$; Fig. 4B).

Post-bypass fetal blood gas parameters and lactate levels are significantly altered. Changes in blood gas parameters and lactate levels post-bypass were recorded, as depicted in Fig. 3. Fetal $\mathrm{pH}, \mathrm{SaO}_{2}$, base excess and lactate values were maintained during arrest (ECC) relative to those pre-bypass (P>0.05; Fig. 5A, D-F). Mean fetal $\mathrm{pH}$ values post-bypass were significantly decreased relative to those pre-bypass $(\mathrm{P}<0.01)$, particularly at 30 and $60 \mathrm{~min}(\mathrm{P}<0.001$; Fig. 5A), while mean fetal $\mathrm{PaO}_{2}$ significantly increased during arrest $(\mathrm{P}<0.05)$, then decreased significantly $120 \mathrm{~min}$ post-bypass relative to the pre-bypass value $(\mathrm{P}<0.05$; Fig. 5B). Mean fetal $\mathrm{PaCO}_{2}$ significantly decreased during arrest $(\mathrm{P}<0.01)$, then significantly increased at all time points post-bypass relative to the pre-bypass value $(\mathrm{P}<0.001$; Fig. $5 \mathrm{C})$, while 
A

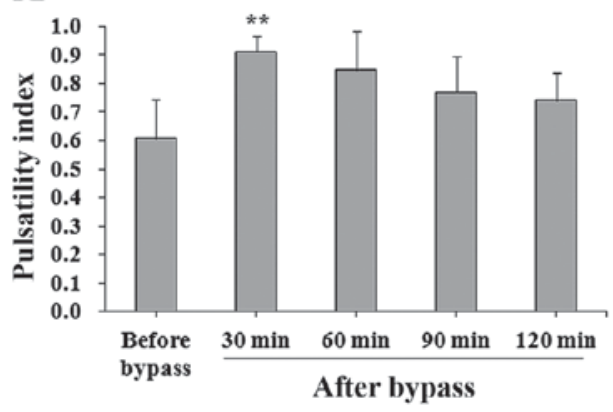

B

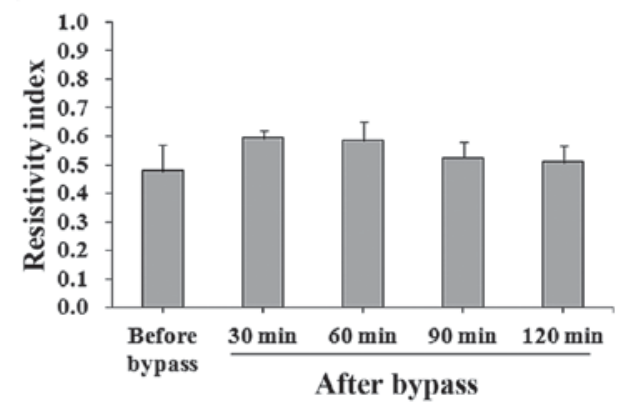

Figure 4. Pulsatility and resistivity indices of umbilical arteries. The placental vascular resistance pre- and 30,60,90 and 120 min post-bypass was measured via calculation of the (A) pulsatility index and (B) resistivity index at set time points. Data are presented as the mean \pm standard deviation ( $\mathrm{n}=6$ ). ${ }^{* * *} \mathrm{P}<0.01$ vs. pre-bypass values.

A

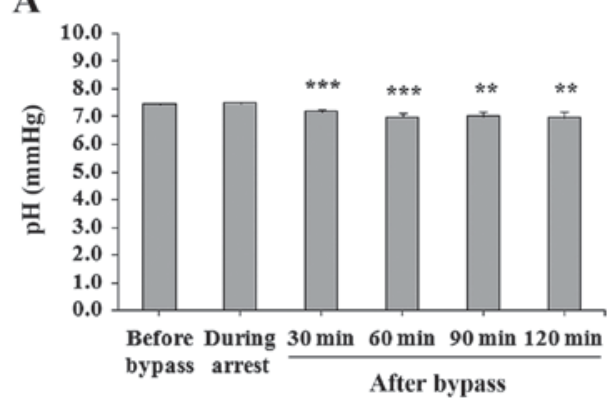

C

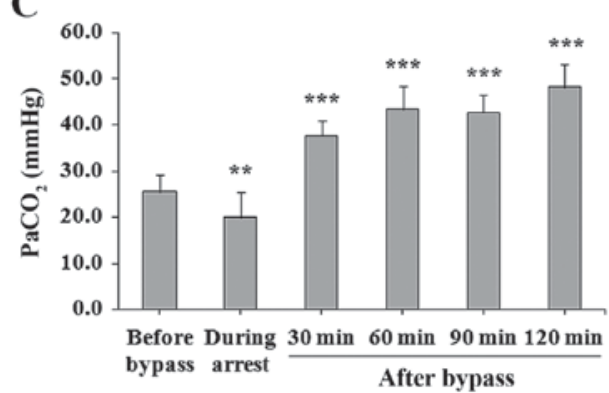

$\mathbf{E}$

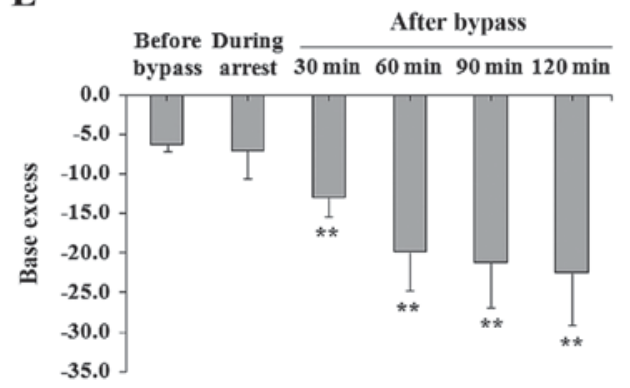

B

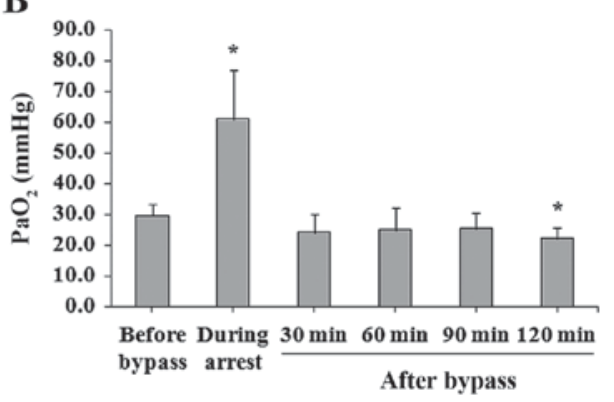

D

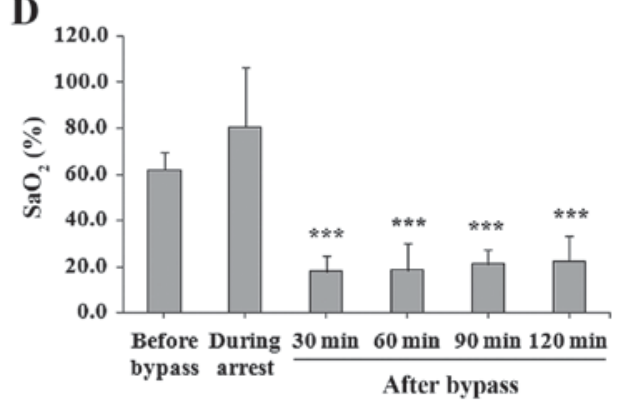

F

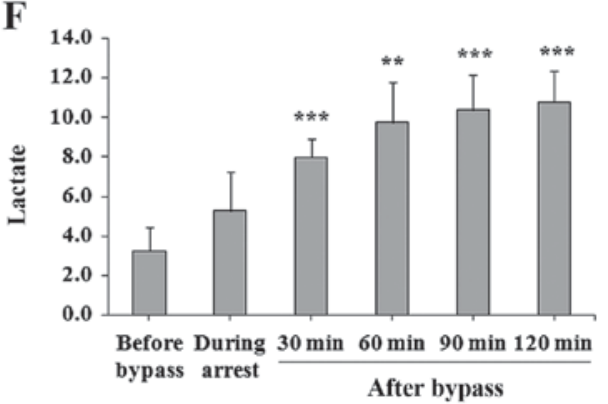

Figure 5. Fetal blood gas parameters pre- and post-bypass. The fetal blood gas levels of (A) pH, (B) $\mathrm{PaO}_{2},(\mathrm{C}) \mathrm{PaCO}_{2}$, (D) $\mathrm{SaO}$, (E) base excess (F) and lactate were measured immediately prior to and during bypass, then at set-time intervals (30, 60, 90 and 120 min) post-bypass. Data are presented as the mean \pm standard deviation $(\mathrm{n}=6) .{ }^{*} \mathrm{P}<0.05,{ }^{* *} \mathrm{P}<0.01$ and ${ }^{* * *} \mathrm{P}<0.001$ vs. pre-bypass values.

post-bypass mean fetal $\mathrm{SaO}_{2}$ values significantly decreased at all time points relative to the pre-bypass value $(\mathrm{P}<0.001$; Fig. 5D). Mean fetal base excess levels were significantly lower at all time points post-bypass relative to the pre-bypass level $(\mathrm{P}<0.01$; Fig. 5E), and mean lactate values at all time points post-bypass were significantly increased relative to the pre-bypass value $(\mathrm{P}<0.01)$, particularly at 30,90 and $120 \mathrm{~min}$ $(\mathrm{P}<0.001$; Fig. 5F).

\section{Discussion}

The present study assessed the impact of total ECC on hemodynamics in an ovine fetal model. During the ECC period, the umbilical chord and ascending aorta were clamped, with the latter causing fetal heart arrest. In this model, fetal circulation was dependent on ECC with no contribution from placental blood flow. The in vivo results indicated that the 
ascending aorta and umbilical cord can be occluded during ECC for $\leq 30 \mathrm{~min}$, with stable fetal hemodynamics achieved following reperfusion without the need for pharmacological or mechanical support. Following total ECC and cardioplegic arrest, fetal hemodynamics and placental function remained stable up to $2 \mathrm{~h}$ following reperfusion.

In the present study, umbilical chord and ascending aorta clamping rendered membrane oxygenation as the sole oxygenator. In previous CPB ovine fetal models, the placenta served as the sole oxygenator, resulting in unstable oxygenation and severe placental damage occurring $(24,25)$. It was observed that inhibiting stress and protecting vascular endothelial function of the placenta following CPB prevented an increase in the vascular resistance of the placenta that would otherwise lead to impairment of placental function, irreversible acidosis and subsequent fetal death (24). During $\mathrm{CPB}$, the following typically influence the extent of placental damage: i) Re-distribution of fetal blood flow, ii) placental vascular endothelial dysfunction, iii) humoral factors, iv) perfusion patterns, v) pre-perfusion solution, and vi) low temperatures (25). Synergistic effects of these factors may cause progressive hypoxia, hypercapnia, acidosis and mortality of the fetuses $(20,26)$. Therefore, in CPB, particularly within fetal cardiac arrest models, the placenta is not considered to be a stable oxygenator.

A methodology for fetal ECC in ovine models has been determined that includes cardiac arrest and maintenance of intact placental circulation (27). In one study, post-bypass placental gas exchange function was preserved in fetal lambs when the placenta was excluded from the bypass circuit (13), while another study used centrifugal pumps and polymethyl pentene oxygenators to establish ovine models of extracorporeal life support without extracorporeal-related inflammation and tissue injury (27). In the current total ECC model, fetal circulation depended solely upon ECC with no contribution from placental blood flow, with the ECMO as the sole oxygen source. As such, the present methodology appears to mimic the clinical scenario in which newborns undergo CPB for repair of CHD.

The present study employed the pulsatility and resistivity indices in order to evaluate placental resistance pre-and post-arrest. Increased pulsatility and resistivity indices of the umbilical arteries are considered to indicate placental injury due to higher vascular resistance (17). In the present study, higher pulsatility and resistivity indices were observed in the early post-bypass period, with the increase in pulsatility determined to be significant $(\mathrm{P}<0.01)$, relative to pre-bypass values. However, these indices recovered by $90 \mathrm{~min}$ post-bypass. Furthermore, at $30 \mathrm{~min}$ post-arrest, the reperfused placenta exhibited almost normal vascular resistance. A previous study by Sebastian et al (28) used a disposable centrifugal pump as the ECC with the aim of improving vascular hemodynamics. The TinyPump device, developed in Japan, reduced the extracorporeal surface area and avoided external priming substances, particularly blood from adult sources that has lower oxygen affinity. Thus, the device was considered to be suitable for fetal CPB in an ovine model.

In a previous study utilizing fetal cardiac bypass in an ovine model, fetal systolic dysfunction (with lower preload recruitable stroke work) and diastolic dysfunction (with increased time constant of isovolumic relaxation and a lower derivative of pressure/change over time) was observed post-bypass in the ventricles (29). However, cardiac output was found to be lower and end-diastolic pressures were higher in the RV, though not in the LV, post-bypass (29). In the present study, the Tei index increased significantly in the ventricles post-arrest $(\mathrm{P}<0.05)$. Similarly, in a late third-trimester goat model, LV and RV myocardial dysfunction was observed (30), with an increased Tei index value $1 \mathrm{~h}$ after CPB. The separate evaluation of RV and LV dysfunction provides information on the sensitivity of each ventricle to hemodynamic alterations during bypass, which may then affect fetal blood composition (29). Although CPB and fetal cardiac arrest may collectively cause left and right ventricular dysfunction, changes in LV function following CPB are not identical to changes in RV function, and deterioration of RV diastolic function is also more apparent $(17,21,29)$. The applications of ventricular function data in ovine models are limited, due to the sheep heart having greater ventral tilted along the long axis compared with the human heart. This leads to difficulties in performing standard echocardiographic measurements of ventricular function in the ovine fetus, due to distorted ventricular geometry, preload and afterload (11). By contrast, the Tei index applies nongeometric assessment and overcomes such difficulties inherent to geometric assessment of LV and RV function (30). This suggests that it is a sensitive indicator of fetal ventricular dysfunction following cardioplegic arrest, particularly in the evaluation of ventricular dysfunction post-bypass.

In the present study, fetal cardiac dysfunction, particularly $\mathrm{RV}$ diastolic dysfunction, is a likely factor affecting fetal blood gas and lactate levels. The fetal RV, as the supplier of coronary and upper body circulation, was found to be the main pumping chamber, with a higher output than the LV. This was evident from the EDP values for each measurement, as recorded by pressure catheters. Similarly, previous results have indicated that RV wall stress at comparable transmural systolic pressures are greater than those of the LV, and may contribute to lower RV cardiac output (28). Therefore, protecting and preserving fetal myocardial function, particularly the apparent dominant RV function, are key aspects of fetal intracardiac repair. Petrucci et al (21) observed that RV myocardial contractility was better preserved following fibrillatory arrest compared with a common cardioplegia arrest. Nevertheless, while fetal bypass studies often focus on maintaining placental function, avoiding injury to the fetal myocardium during and following CPB is necessary for fetal survival and subsequent development.

The present study included key limitations. Fetal cardiac and placental functions were recorded on only one occasion prior to fetal cardiac arrest. Furthermore, data regarding the long-term survival of the fetal sheep were lacking. Therefore, further studies are warranted in order to confirm the results of the present study and to collect data on the long-term survival of the fetal sheep.

In conclusion, the present study established an ovine fetal bypass model that enabled performance of adequate fetal systemic perfusion, successful cardioplegic arrest, effective weaning from ECC and resumption of normal placental gas exchange following bypass. This novel ECC model provides a reproducible and feasible method for future studies into 
post-CPB pathophysiology and fetal hemodynamics, fetal cardiac arrest and open-heart surgery in fetal sheep. In turn, defining the mechanisms of fetal myocardial dysfunction, placental dysfunction and protection in ovine models may have key implications for human fetal cardiac surgery. Therefore, the results of the present study may aid in improving the open surgical correction of heart deformations in humans.

\section{Acknowledgements}

This study was supported by grants from the National Natural Science Foundation of China (No. 81370274).

\section{References}

1. American Heart Association (AHA): Youth and cardiovascular diseases statistics. American Heart Association, 2004.

2. Sklansky M: New dimensions and directions in fetal cardiology. Curr Opin Pediatr 15: 463-471, 2003.

3. Becker S, Hofbeck M, Kendziorra H, Wallwiener D and Mielke G: Double-chamber right ventricle associated with severe fetal cardiac failure. Ultrasound Obstet Gynecol 23: 411-413, 2004.

4. Glatz JA, Tabbutt S, Gaynor JW, Rome JJ, Montenegro L, Spray TL and Rychik J: Hypoplastic left heart syndrome with atrial level restriction in the era of prenatal diagnosis. Ann Thorac Surg 84: 1633-1638, 2007.

5. Maeda K, Yamaki S, Kado H, Asou T, Murakami A and Takamoto S: Hypoplasia of the small pulmonary arteries in hypoplastic left heart syndrome with restrictive atrial septal defect. Circulation 110 (11 Suppl 1): II139-46, 2004.

6. Sharland GK, Chita SK and Allan LD: Tricuspid valve dysplasia or displacement in intrauterine life. J Am Coll Cardiol 17: 944-949, 1991.

7. Trines $\mathrm{J}$ and Hornberger LK: Evolution of heart disease in utero. Pediatr Cardiol 25: 287-298, 2004.

8. Taketazu M, Barrea C, Smallhorn JF, Wilson GJ and Hornberger L: Intrauterine pulmonary venous flow and restrictive foramen ovale in fetal hypoplastic left heart syndrome. J Am Coll Cardiol 43: 1902-1907, 2004.

9. Michelfelder E, Gomez C, Border W, Gottliebson W and Franklin C: Predictive value of fetal pulmonary venous folw patterns in identifying the need for atrial septoplasty in the newborn with hypoplastic left ventricle. Circulation 112: 2974-2979, 2005.

10. Turley K, Vlahakes GJ, Harrison MR, Messina L, Hanley F, Uhlig PN and Ebert PA: Intrauterine cardiothoracic surgery: The fetal lamb model. Ann Thorac Surg 34: 422-426, 1982.

11. DiVincenti L Jr, Westcott R and Lee C: Sheep (Ovis aries) as a model for cardiovascular surgery and management before, during, and after cardiopulmonary bypass. J Am Assoc Lab Anim Sci 53: 439-448, 2014.

12. Slate RK, Richter RC, Rudolph Amand Turley K: Cardioplumonary bypass in fetal lambs: A technique for intrauterine cardiac surgery. Circulation 70 (Suppl II): II285, 1984.

13. Fenton KN, Zinn HE, Heinemann MK, Liddicoat JR and Hanley FL: Long-term survivors of fetal cardiac bypass in lambs. J Thorac Cardiovasc Surg 107: 1423-1427, 1994.

14. Reddy VM, Liddicoat JR, Klein JR, Wampler RK and Hanley FL: Long-term fetal outcome after fetal cardiac bypass: Fetal survival to full term and organ abnormalities. J Thorac Cardiovasc Surg 111: 536-544, 1996.
15. Malhotra SP, Thelitz S, Riemer RK, Reddy VM, Suleman S and Hanley FL: Fetal myocardial protection is markedly improved by reduced cardioplegic calcium content. Ann Thorac Surg 75: 1937-1941, 2003.

16. Malhotra SP, Thelitz S, Riemer RK, Reddy VM, Suleman S and Hanley FL: Induced fibrillation is equally effective as crystalloid cardioplegia in the protection of fetal myocardial function. J Thorac Cardiovasc Surg 125: 1276-1282, 2003.

17. Liu XB, Zhou CB, Chen JM, Cen JZ, Xu G and Zhuang J: A fetal goat model of cardiopulmonary bypass with cardioplegic arrest and hemodynamic assessment. J Thorac Cardiovasc Surg 142: 1562-1566, 2011.

18. Lam C, Baker RS, McNamara J, Ferguson R, Lombardi J, Clark K and Eghtesady P: Role of nitric oxide pathway in placental dysfunction following fetal bypass. Ann Thorac Surg 84: 917-925, 2007.

19. Baker RS, Lam CT, Heeb EA and Eghtesady P: Dynamic fluid shifts induced by fetal bypass. J Thorac Cardiovasc Surg 137: 714-722, 2009.

20. Lam CT, Sharma S, Baker RS, Hilshorst J, Lombardi J, Clark KE and Eghtesady P: Fetal stress response to fetal cardiac surgery. Ann Thorac Surg 85: 1719-1727, 2008.

21. Petrucci O, Baker RS, Lam CT, Reed CA, Duffy JY and Eghtesady P: Fetal right ventricular myocardial function is better preserved by fibrillatory arrest during fetal cardiac bypass. Ann Thorac Surg 90: 1324-1331, 2010.

22. Menzel T, Kramm T, Mohr-Kahaly S, Mayer E, Oelert H and Meyer J: Assessment of cardiac performance using Tei indices in patients undergoing pulmonary thromboendarterectomy. Ann Thorac Surg 73: 762-766, 2002

23. Tei C, Nishimura RA, Seward JB and Tajik AJ: Noninvasive doppler-derived myocardial performance index: Correlation with simultaneous measurements of cardiac catheterization measurements. J Am Soc Echocardiogr 10: 169-178, 1997.

24. Oishi Y, Masuda M, Yasutsune T, Boku N, Tokunaga S, Morita S and Yasui H: Impaired endothelial function of the umbilical artery after fetal cardiac bypass. Ann Thorac Surg 78: 1999-2004, 2004.

25. Vedrinne C, Tronc F, Martinot S, Robin J, Allevard AM, Vincent M, Lehot JJ, Franck M and Champsaur G: Better preservation of endothelial function and decreased activation of the fetal renin-angiotensin pathway with the use of pulsatile flow during experimental fetal bypass. J Thorac Cardiovasc Surg 120: 770-777, 2000

26. Su Z, Zhou C, Zhang $\mathrm{H}$ and Zhu Z: Hormonal and metabolic responses of fetal lamb during cardiopulmonary bypass. Chin Med J (Engl) 116: 1183-1186, 2003.

27. Shekar K, Fung YL, Diab S, Mullany DV, McDonald CI, Dunster KR, Fisquet S, Platts DG, Stewart D, Wallis SC, et al: Development of simulated and ovine models of extracorporeal life support to improve understanding of circuit-host interactions. Crit Care Resusc 14: 105-111, 2012.

28. Sebastian VA, Ferro G, Kagawa H, Nasirov T, Maeda K, Ferrier WT, Takatani S, Riemer RK, Hanley FL and Reddy VM: Fetal cardiac intervention: Improved results of fetal cardiac bypass in immature fetuses using the TinyPump device. J Thorac Cardiovasc Surg 145: 1460-1464, 2013.

29. Duffy JY, Petrucci O, Baker RS, Lam CT, Reed CA, Everman DJ and Eghtesady P: Myocardial function after fetal cardiac bypass in an ovine model. J Thorac Cardiovasc Surg 141: 961-968, 2011

30. Zhou CB, Zhuang J, Zhang X and Zhang J: Changes in atrial natriuretic peptide levels during cardiac bypass in the fetal goat. Artif Organs 32: 956-961, 2008. 